\title{
Market structure in the US electricity industry: A long-term perspective
}

\author{
David R. Kamerschen ${ }^{\mathrm{a}, *}$, Peter G. Klein ${ }^{\mathrm{b}}$, David V. Porter ${ }^{\mathrm{c}}$ \\ ${ }^{a}$ Department of Economics, Terry College of Business, The University of Georgia, Athens, \\ GA 30602, United States \\ ${ }^{\mathrm{b}}$ Contracting and Organizations Research Institute, The University of Missouri, \\ Columbia, MO 65211, United States \\ ${ }^{\mathrm{c}}$ E-minus Energy Trading, United States
}

Received 22 July 2004; accepted 30 March 2005

Available online 14 July 2005

\begin{abstract}
We estimate changes in market structure in the US electric power industry during the last three decades using two independent approaches. First, we estimate an industry-wide conjectural-variations parameter. We find that industry concentration was generally rising during the 1970s, but has been gradually and consistently falling since the early 1980s. To check the robustness of these results, we then use a translog production function to estimate the Lerner Index. The results confirm that the industry was becoming less concentrated during the 1980s, though the Lerner Index tended to fluctuate during the late 1980s and early 1990s. Our results suggest that the current state of the electricity industry may have more to do with long-term changes in market structure than recent attempts to establish competitive wholesale electricity markets.
\end{abstract}

(C) 2005 Elsevier B.V. All rights reserved.

JEL classification: L10; L51; L94

Keywords: Electricity markets; Concentration; Conjectural variations; Lerner Index

* Corresponding author. Tel.: +1 7065423681.

E-mail address: davidk@terry.uga.edu (D.R. Kamerschen). 


\section{Introduction}

Since the 1930s electric utilities have been regulated by the states in which they provide service. Nominal and real electric prices dropped from 1930 to 1960 as power plants became larger and more efficient and fuel costs fell. This changed in the 1970s, as fuel prices, especially oil, soared. The Department of Energy was created in 1977 along with an independent regulatory authority, the Federal Energy Regulatory Commission, that assumed most of the statutory duties of the former Federal Power Commission. The 1978 Public Utility Regulatory Policies Act (PURPA) was passed to deal with these fuel constraints, and subsequently large utilities began facing competition from small independent producers and their own large industrial customers. ${ }^{1}$

Congress formally deregulated the wholesale electric market with the Energy Policy Act of $1992 .^{2}$ On April 1, 1998, the largest electric power market in the US, California, further pushed competition by allowing utility ratepayers to buy from any supplier they choose. At the time, other states such as Massachusetts, New Hampshire, New Jersey, New York, Oregon, Pennsylvania, and Rhode Island were in various states of restructuring their electricity markets. According to the Department of Energy's (DOE) September 2000 deregulation update, twenty-three states had enacted deregulation legislation, while another twenty had orders pending or ongoing legislative deregulation investigations. However, while by 2005, eighteen states had deregulated, they did so by retaining control of the "wires" or delivery side of the business, but removing restrictions on the generation and sale of electricity (Smith, 2005).

Recent research on electric-market competition has generally focused on the effects of introducing formal markets for wholesale power ${ }^{3}$ and price spikes and supply problems in California in 2000-2001 and elsewhere. These studies raise questions about the effectiveness of these markets. However, there is relatively little evidence on the longterm trends in the market structure of the US electricity industry following the oil shocks of the 1970s. If concentration, strategic interaction, and other market characteristics are affected by technology, firm organization and governance, the legal environment, and similar factors besides the creation of formal wholesale markets, then a broader perspective may be necessary to understand the effects of recent policy changes on market structure and performance. ${ }^{4}$

We examine market structure in the US electric utility industry from the 1970s to the 1990s. Our results are interesting. First, using a conjectural-variations (CV) approach, we find that electricity markets became less concentrated beginning in the 1980s, with little

\footnotetext{
${ }^{1}$ Their response was to fight the new Carter-inspired competition all the way to the U.S. Supreme Court, eventually losing in the early 1980 s.

2 Throughout the paper we use the term "deregulation" as shorthand for the introduction of limited marketbased incentives into wholesale or retail markets. Obviously we do not refer to complete deregulation, but rather the partial deregulation characterizing most restructuring programs.

3 See, e.g., Wolfram, 1999.

${ }^{4}$ Danielsen et al. (1999), for example, show how the effects of restructuring depend on courts' attitude toward contractual breaches. When restructuring alters the existing "regulatory compact", electricity-market participants increasingly look to renegotiate contractual agreements signed under previous regulatory regimes (to reduce stranded costs, for instance).
} 
change in the trend following the reforms of the 1990s. Second, we use a structural model to estimate a Lerner Index for US electricity markets for part of our sample period, 19811998. The Lerner approach largely confirms the results of the CV approach; namely, electricity markets became less concentrated during the 1980s (with mixed results during the 1990s). In short, changes in the industry prior to the $1990 \mathrm{~s}$ - primarily technological change, combined with modest deregulation - appear to have had a greater impact than previously acknowledged. This suggests that the creation of wholesale (and later retail) markets for electricity should not be characterized as a radical innovation, but rather the continuation of a secular trend.

The remainder of the paper is organized as follows. Section 2 outlines the conjecturalvariations framework we use here. Section 3 applies this framework to the US electricity and presents our estimates. Section 4 presents our structural analysis, describing the translog production function and providing our estimates of market concentration.

\section{Conjectural-variations models of industry structure}

The conjectural-variations approach is easily illustrated with a standard Cournot model. Consider a symmetric Cournot game with a homogeneous product where $q=$ industry output, $p(q)$ is the industry inverse demand curve, and costs are given by $c(q)$. Firm $i$ 's reaction function is given by differentiating the profit function $\pi_{i}$ with respect to $q_{i}$ :

$$
\frac{\mathrm{d} \pi_{i}}{\mathrm{~d} q_{i}}=p+\frac{\mathrm{d} p}{\mathrm{~d} q} q_{i}-\frac{\mathrm{d} c}{\mathrm{~d} q_{i}}=0 .
$$

Firm $i$ 's conjectural variation describes its belief about how other firms' output will change in response to a change in its output. To incorporate this belief, Eq. (1) can be rewritten as follows:

$$
\frac{\mathrm{d} \pi_{i}}{\mathrm{~d} q_{i}}=p+\frac{\mathrm{d} p}{\mathrm{~d} q} \frac{\mathrm{d} q}{\mathrm{~d} q_{i}} q_{i}-\frac{\mathrm{d} c}{\mathrm{~d} q_{i}}=0 .
$$

The difference between (1) and (2) is that $q_{i}$ is multiplied by

$$
\frac{\mathrm{d} q}{\mathrm{~d} q_{i}}=1+\frac{\mathrm{d} q_{-i}}{\mathrm{~d} q_{i}},
$$

where $q_{-i}$ denotes the joint output of all firms other than $i$. Eq. (3) shows that there are two effects on industry output when firm $i$ increases its output: the direct effect of firm $i$ increasing output, and an indirect effect when the other firms change their output in response to firm $i$. Let $v_{i}$ be firm $i$ 's belief - correct or not-about the other firms' reactions to its action. Call $v_{i}=\mathrm{d} q_{-i} / \mathrm{d} q_{i}$ the conjectural variation for firm $i$. That is,

$$
\frac{\mathrm{d} q}{\mathrm{~d} q_{i}}=1+v_{i}
$$

Substituting (4) into (2) yields

$$
\frac{\mathrm{d} \pi_{i}}{\mathrm{~d} q_{i}}=p+\frac{\mathrm{d} p}{\mathrm{~d} q}\left(1+v_{i}\right) q_{i}-\frac{\mathrm{d} c}{\mathrm{~d} q_{i}}=0 .
$$


There are three ways to interpret the structure of the industry, depending on the value of the conjectural variation term.

(1) $v_{i}=0$. This represents the Cournot-Nash equilibrium. Firm $i$ believes that if it increases output, its rivals will not respond.

(2) $v_{i}=-1$. This is the perfectly competitive assumption. When $v_{i}=-1$, firm $i$ believes that an increase in its output will be matched by a decrease in the output of the other firms. A change in output by one firm will leave industry output unchanged. If all firms hold this conjecture, then industry output will be at the perfectly competitive level. Firms believe that an increase in their own output will not affect the price they receive.

(3) $v_{i}=+1$. This is the monopoly assumption: firm $i$ believes that its rivals will exactly match any output changes. In a two-firm game, the industry output will be the monopoly level. In an $n$-firm game $v_{i}=n-1$ yields the monopoly output. ${ }^{5}$

Iwata (1974) proposed a method for estimating the conjectural variation parameter for an entire industry. It was the first attempt to provide an objective numerical measure of industry-wide market structure rather than a descriptive measure. He studied the Japanese flat-glass industry from 1956 to 1965 and presented a statistical test to (1) determine if the conjectural variation parameter was a specified value, and (2) test the hypothesis that a certain type of collusion between firms was present. In his model, the profit-maximizing behavior for all the individual firms in a given industry is

$$
p+\frac{\mathrm{d} p}{\mathrm{~d} q}\left(1+v_{j}\right) q_{j}-m c_{j}=0,
$$

where $j=(1, \ldots, n)$, and $\mathrm{mc}_{j}=\mathrm{d} C_{j} / \mathrm{d} q_{j}$. If the price elasticity of demand is written as $\eta$, then (6) can be re-written as

$$
p+\frac{1}{\eta} \frac{p}{q}\left(1+v_{j}\right) q_{j}-m c_{j}=0
$$

for the entire industry where $j=(1, \ldots, n)$. The market share of firm $j, q_{j} / q$, can be expressed as

$$
\frac{q_{j}}{q}=\frac{\eta}{p} \times \frac{m c_{j}-p}{1+v_{j}} .
$$

The individual firms' output shares on the left-hand side should sum to one. Eq. (8) can be re-written as

$$
p=\left(\eta \sum \frac{m c_{j}}{1+v_{j}}\right) /\left(\eta \sum \frac{1}{1+v_{j}}+1\right)
$$

\footnotetext{
5 This class of models has been criticized for failing to explain how firms form their beliefs. Daughety (1985) responds to this criticism by suggesting that an "infinite regress" could lead to the beliefs assumed by static gametheoretic models. Infinite regress describes the situation where Firm 1's manager tries to think about what Firm 2's manager thinks about what Firm 1's manager is thinking and so on. In such a situation, Daughety shows that each firm chooses to maximize profits based on output levels, and the Cournot conjecture is appropriate.
} 
The market price level can be expressed in terms of three factors, the price elasticity of demand $(\eta)$, the marginal costs of the individual firms $\left(m c_{j}\right)$, and the conjectural variation term $\left(v_{j}\right)$.

Rewriting Eq. (7) in terms of $v_{j}$,

$$
v_{j}=\eta \frac{m c_{j}-p}{p} \frac{q}{q_{j}}-1
$$

shows that the conjectural variation term is a function of the price elasticity of demand $(\eta)$, the individual firm's marginal cost $\left(m c_{j}\right)$, and each firm's market share $\left(q / q_{j}\right)$.

Market shares can readily be compiled from industry sales data. However, the individual firm's marginal cost $\left(m c_{j}\right)$ and the price elasticity of demand for the industry must be estimated. Iwata makes two simplifying assumptions. First, he assumes that the demand function is log-linear. Consequently, the demand elasticity estimate will be constant, regardless of the level of demand. Second, the marginal cost $\left(m c_{j}\right)$ of each firm is assumed to be constant with respect to short-run output variations.

Appelbaum (1982) uses a similar approach to estimate the conjectural-variation parameter for four US industries, rubber, textile, electrical machinery, and tobacco. ${ }^{6}$ Appelbaum provides a measure of the degree of oligopolistic power of an individual firm, and creates an index to measure the degree of oligopoly in a particular industry. His model is based on an oligopolistic industry consisting of $s$ firms. The $s$ firms use $n$ inputs, $x=\left(x_{1}, \ldots, x_{n}\right)$ to produce a homogenous output $y$. The cost function of the $j$ th firm is $C^{j}=C^{j}\left(q^{j}, w\right)$ where $q^{j}$ is the $j$ th firm's output, and $w$ is a vector of input prices. The industry faces market demand schedule

$$
q=J(p, z)
$$

where $p$ is the price of $q$, and $z$ is a vector of exogenous variables such as the prices or quantities of other inputs or outputs consumed by the demanders of output $q$.

Appelbaum invokes Shephard's lemma to derive input demand functions. He assumes that all of the firms in the industry are price takers on the input side. Perfectly competitive input markets are the critical assumption of his model. According to Shephard's lemma,

$$
x^{j}=\partial C^{j}\left(q^{j}, w\right) / \partial w, \quad j=1, \ldots, s .
$$

The $j$ th firm's profit maximization is

$$
\max \left[p q^{j}-C^{j}\left(q^{j}, w\right): q=J(p, z)\right],
$$

and

$$
q=\sum_{j=1}^{s} q^{j}
$$

\footnotetext{
${ }^{6}$ Fischer and Kamerschen (2003) use this approach for an analysis of the US airline industry.
} 
is industry supply. This means the profit-maximization first-order conditions are

$$
p\left(1-\theta^{j} \epsilon\right)=\partial C^{j}\left(q^{j}, w\right) / \partial q_{j},
$$

where $\theta^{j}$, defined as $\theta^{j}=\left(\partial q / \partial q^{j}\right)\left(q^{j} / q\right)$, is the conjectural elasticity of industry output with respect to the $j$ th firm's output and $\epsilon$, defined as $\epsilon=-(\partial p / \partial q)(p / q)$, is the absolute value of the inverse market demand elasticity. $\theta^{j}$ is equal to $\left(1+v_{j}\right)$, which is one plus each firm's conjectural variation. According to (15) the firm equates its perceived marginal revenue to its marginal cost.

The Cournot, perfectly competitive and monopoly values of $\theta^{j}$ must be considered. The $\left(q^{j} / q\right)$ portion of $\theta^{j}$ is each firm's output share. In the Cournot case, $\left(\partial q / \partial q^{j}\right)=1$, and $\theta^{j}$ is each firm's output share. In the perfectly competitive case, $\left(\partial q / \partial q^{j}\right)=0$, and therefore $\theta^{j}=0$. In the monopoly case, the entire industry will produce the same output as a single profit-maximizing firm, $q=q^{j}$, and $\theta^{j}=1$. Rewriting (15) and defining

$$
a_{j}=\left[p-\partial C^{j}\left(q^{j}, w\right) / \partial q_{j}\right] / p=\theta_{j} \epsilon,
$$

as the degree of monopoly power of the $j$ th firm allows us to make some inferences about the magnitude of $\alpha_{j}$. We know that marginal costs are nonnegative, $\alpha_{j} \geq 0$. Since $\alpha_{j}$ is composed of the inverse elasticity of demand 0 , and conjectural elasticity $\theta^{j}$, then $\alpha_{j} \leq 1$. In the inverse elasticity of demand, 0 will always be less than one, and only in the case of a pure monopolist will $\theta^{j}=1$, resulting in an upper bound of $\theta^{j} \leq 1$.

We can aggregate (16) to determine the degree of monopoly power of the entire industry,

$$
L=\sum\left[\left(p-m c_{j}\right) / p\right] s_{j}=\sum_{j} a_{j} s_{j}=\sum_{j} \theta^{j} \epsilon
$$

where $s_{j}=\left(\partial q / \partial q^{j}\right)$, and $\mathrm{mc}_{j}$ is the marginal cost of the $j$ th firm. This industry measure is very similar to the approach by Cowling and Waterson (1976). Since $\theta^{j}=\left(\partial q / \partial q^{j}\right)\left(q^{j} /\right.$ $q)=\left(\partial q / \partial q^{j}\right) s_{j}$, the far right-hand term of (17) can be rewritten as

$$
L=\sum_{j} \frac{\partial q}{\partial q^{j}} s_{j}^{2} \epsilon .
$$

The measure of industry oligopoly power is equal to the sum of squared firm shares weighted by the firm's conjectural elasticity, and multiplied by the inverse demand elasticity.

If firm-specific input and output time series are available for the industry, the full model can be estimated by the systems (11), (12), and (15). Since firm-specific data are much more difficult to find, Appelbaum assumes that firms have linear and parallel expansion paths so that he can use aggregate data instead. In other words, the firms' cost functions are in Gorman polar form (Gorman, 1953). With regard to (12), the aggregate demand function for the $i$ th input is

$$
x_{i}=\sum_{j} x_{i}^{j}=\sum_{j} \partial C^{j}\left(q^{j}, w\right) / \partial w_{i}, \quad i=1, \ldots, n .
$$


Firms' cost functions, which are of Gorman polar form and have linear and parallel expansion paths, take the form

$$
C^{j}\left(q^{j}, w\right)=q^{j} C(w)+G^{j}(w), \quad j=1, \ldots, s .
$$

According to Blackorby, Primont, and Russell (1977), if the cost functions are of Gorman polar form, firms' marginal costs will be constant and equal across firms. Due to this assumption, the aggregate input demand functions will be

$$
x=q[\partial C(w) / \partial w]+\sum_{j} \partial G^{j}(w) / \partial w
$$

and can be expressed in aggregate industry variables rather than firm-specific data.

Given (21), if we assume that $\theta^{j}$ are the same for all firms in the industry, then (15) will become $p(1-\theta \epsilon)=C(w)$ on the aggregate level. This may seem troublesome, because it assumes that all firms behave similarly. Such worries can be assuaged, if we consider the maximizing behavior implied by (15). It means that firms equate their perceived marginal revenues to their marginal cost. If all firms face the same input costs, then in equilibrium, each firm must have the same conjectural elasticities $\left(\theta^{j}\right)$. It is not required that the individual firms have the same perceived marginal revenue curves. In equilibrium each firm will move down its respective curve until its perceived level of marginal revenues is equal to marginal cost. By this reasoning, we can rewrite the optimality condition in (15) as

$$
p(1-\theta \varepsilon)=C(w) .
$$

The value of $\theta$ is equal to the output share in the Cournot case, 0 in the perfectly competitive case, and 1 in the monopoly case. The model yields an estimate of $\theta$ that indicates how far the industry deviates from the perfectly competitive solution in which $\theta=0$. The measure of oligopoly power (17) becomes

$$
L=\theta \varepsilon .
$$

If the industry is perfectly competitive, the Lerner Index equals zero $(L=0)$, since $\theta=0$. If the industry is monopolistic, the Lerner Index equals the inverse elasticity of demand $(L=0)$, since $\theta=1$.

Eqs. (11), (21), and (22) provide the system of optimality equations for the entire industry. Since $\theta$ is not a constant, but rather a function of the exogenous variables, $\theta$ is estimated at the equilibrium points as a linear function of the exogenous variables.

\section{Conjectural-variations estimates for the US electricity industry}

\subsection{Empirical approach}

Using Appelbaum's framework for aggregate output and input prices and quantities, we estimate the degree of oligopoly in the US electric utility industry. We assume that the 
input markets are perfectly competitive and that US firms face the same prices for three inputs, labor $x_{l}$, capital $x_{k}$, and fuel $x_{f}$, whose prices are $w_{l}, w_{k}$, and $w_{f}$, respectively.

The electricity demand function is specified as a Cobb-Douglas function

$$
\ln q=a-\eta \ln (p / S)=\rho \ln (y / S),
$$

where $S$ is the implicit GDP price deflator, and $y$ is GDP in current dollars. The demand elasticity is $(\eta)$ is assumed to be an absolute value and $\eta=1 / 0$.

The industry cost function is assumed to be a generalized Leontief cost function (Diewert, 1971), which is a specific version of the Gorman polar form. Appelbaum (1979) discusses the advantages of generalized Leontief functions. He chooses this form because it is flexible, and also provides a second-order approximation of a technology that makes no assumption regarding returns to scale. The generalized Leontief cost function has the form

$$
c=\sum_{i} \sum_{j} b_{i j}\left(w_{i} w_{j}\right)^{1 / 2} q+\sum_{i} b_{i} w_{i}, \quad i, j=K, L, F,
$$

where

$$
b_{i j}=b_{j i} \text { and } \sum b_{i} w_{i}=\sum_{j} G^{j}(w) .
$$

The equilibrium value of the conjectural elasticity is a function of the exogenous variables $\theta=\theta(w)$, which allows $\theta$ to vary over time with changes in the economy.

The full model for the electric utility industry is

$$
\begin{aligned}
& x_{K} / q=b_{K K}+b_{K L}\left(w_{L} / w_{K}\right)^{1 / 2}+b_{K F}\left(w_{F} / w_{K}\right)^{1 / 2}+b_{K} / q, \\
& x_{L} / q=b_{L L}+b_{K L}\left(w_{K} / w_{L}\right)^{1 / 2}+b_{L F}\left(w_{F} / w_{L}\right)^{1 / 2}+b_{L} / q, \\
& x_{F} / q=b_{F F}+b_{K F}\left(w_{K} / w_{F}\right)^{1 / 2}+b_{L F}\left(w_{L} / w_{F}\right)^{1 / 2}+b_{F} / q, \\
& \ln q=a+\ln \eta(p / S)+\rho \ln (y / S), \\
& p=\left[b_{K K} w_{K}+b_{L L} w_{L L}+b_{F F} w_{F}+2 b_{K L}\left(w_{K} w_{L}\right)^{1 / 2}+2 b_{K F}\left(w_{K} w_{F}\right)^{1 / 2}\right. \\
& \left.\quad+2 b_{L F}\left(w_{L} w_{F}\right)^{1 / 2}\right] /[1-\theta / \eta],
\end{aligned}
$$

where $\theta$ is linearly approximated as

$$
\theta=A_{0}+A_{K} w_{K}+A_{L} w_{L}+A_{F} w_{F} .
$$

Both supply and demand equations appear simultaneously in the system and require a simultaneous estimation technique. The model (27) is assumed to be stochastic because of errors in optimization. The additive disturbance term of the $i$ th equation at time $t$ is defined as $e_{i}(t), t=1, \ldots, T$. The column vector of disturbances at time $\mathrm{t}$ is defined as $e_{t}$. The vector of disturbances is assumed to be joint normally distributed with mean vector zero and nonsingular covariance matrix $\Omega$. The model is simultaneously estimated by the full- 
information maximum-likelihood method. The endogenous variables are $q, p, x_{K}, x_{L}$, and $x_{M}$, and all others are treated as exogenous.

$$
\begin{aligned}
E\left[e^{j}(s) e^{j}(t)\right] & =\Omega & & \text { if } t=s \\
& =0 & & \text { if } t \neq s .
\end{aligned}
$$

We estimate:

(1) the conjectural elasticity for the industry, $\theta$, and

(2) whether $\theta=0$, is the perfectly competitive value of $\theta$. Since $\theta$ is not a constant, and

$$
\theta=A_{0}+A_{K} w_{K}+A_{L} w_{L}+A_{F} w_{F},
$$

we test the null hypothesis that $A_{0}=A_{L}=A_{F}=A_{K}=0$.

\subsection{Sample, data, and empirical methods}

We use data from the Monthly Energy Review, Survey of Current Business, and Moody's Public Utility Manual to conduct our analyses. The first three equations in (27) estimate the cost-share equations of the various inputs. The fourth equation estimates a log-linear demand schedule. None of the parameter estimates in the fourth equation appear in the previous three equations, so there is no attempt to identify the supply equation. A loglinear demand schedule would be appropriate for most industries but perhaps not for electricity demand estimation. During times of severe weather, the electricity supply schedule might be extremely inelastic. It is also possible that during times of severe weather, customers are purchasing large amounts of electricity precisely when the price is highest. When a demand shock occurs, society must move along the production possibility frontier and face higher marginal electricity costs.

Economic intuition suggests that electricity should be a normal good and also have a positive own-price elasticity of demand. The presence of a negative income elasticity estimate, or a positive own-price elasticity estimate should raise suspicions that there is an identification problem. FIML estimates of (27) yield price and income elasticity estimates of -0.82 and -1.13 , respectively. The negative income elasticity estimate causes skepticism of the results. Even more troubling is the fact that the price and income elasticity estimates are both significant at the $1 \%$ level, making it more difficult to reject the questionable income elasticity estimate.

To account for the possible identification problem, we estimate the following modified version of (27),

$$
\begin{aligned}
& x_{K} / q=b_{K K}+b_{K L}\left(w_{L} / w_{K}\right)^{1 / 2}+b_{K F}\left(w_{F} / w_{K}\right)^{1 / 2}+b_{K} / q, \\
& x_{L} / q=b_{L L}+b_{K L}\left(w_{K} / w_{L}\right)^{1 / 2}+b_{L F}\left(w_{F} / w_{L}\right)^{1 / 2}+b_{L} / q, \\
& x_{F} / q=b_{F F}+b_{K F}\left(w_{K} / w_{F}\right)^{1 / 2}+b_{L F}\left(w_{L} w_{F}\right)^{1 / 2}+b_{F} / q,
\end{aligned}
$$




$$
\begin{aligned}
p= & {\left[b_{K K} w_{K}+b_{L L} w_{L}+b_{F F} w_{F}=2 b_{K L}\left(w_{K} w_{L}\right)^{1 / 2}+2 b_{K F}\left(w_{K} w_{F}\right)^{1 / 2}\right.} \\
& \left.+2 b_{L F}\left(w_{L} w_{F}\right)^{1 / 2}\right] /[1-\theta / \eta],
\end{aligned}
$$

which does not include a demand schedule. Kamerschen and Porter (2004) estimate the total electricity demand by 3SLS. Simultaneous equation approaches such as 3SLS can account for the identification problem, unlike a log-linear demand schedule. The 3SLS income elasticity estimates range between about 0.89 and 0.90 depending on the version. These estimates are far more plausible than the -1.13 log-linear income elasticity estimate. The 3SLS price elasticity estimates range from about -0.13 and -0.15 . We substitute the -0.13 price elasticity estimate into (29), and do not utilize the log-linear demand equation. The -0.13 elasticity estimate corresponded to a simultaneous equation estimate that included both heating degree days and cooling degree days.

\subsection{Results}

There are 13 free parameters in Eq. (31) to be estimated since the log-linear demand equation is excluded. The parameter estimates and $t$-statistics appear in Table 1.

The maximum likelihood estimates of the conjectural elasticity and market concentration measure $(L=\theta / \eta)$ appear in Table 2. As the conjectural elasticity term $(\theta)$ approaches 0 , the industry becomes less concentrated.

It is necessary to test whether $\theta=0$ to determine whether the underlying market structure might be perfectly competitive. $\theta$ is evaluated at its sample mean to test if $A_{0}=A_{L}=A_{F}=A_{K}=0$. The results appear in Table 3. The restriction $A_{0}=A_{L}=A_{F}=A_{K}=0$ is a sufficient condition for $\theta=0$. We evaluate $\theta$ at its sample mean to test local significance.

The null hypothesis $A_{0}=A_{L}=A_{F}=A_{K}=0$ is rejected. The one-sided $99 \%$ confidence intervals for $\hat{\theta}$ is less than is greater than 0 , and less than 1 , suggesting that the industry is neither perfectly competitive or monopolistic.

Table 1

Eq. (31) parameter estimates and $t$-statistics

\begin{tabular}{lcr} 
Variable & Parameter estimate & $t$-Statistic \\
\hline$b_{K K}$ & $0.000261 * * *$ & 7.6093 \\
$b_{L L}$ & 0.000489 & 0.0878 \\
$b_{F F}$ & $0.000087^{* * *}$ & 6.4211 \\
$b_{K L}$ & -0.000040 & -0.0964 \\
$b_{K F}$ & $-0.000061^{* * *}$ & -4.6543 \\
$b_{F L}$ & $0.000442^{* * *}$ & 6.8898 \\
$b_{K}$ & -217.372300 & -1.6597 \\
$b_{L}$ & $10,056.080000$ & 1.5112 \\
$b_{F}$ & $-200.653200^{* * *}$ & -12.853 \\
$A_{O}$ & $0.146872 *$ & 2.5354 \\
$A_{K}$ & $0.000442 * * *$ & 6.0772 \\
$A_{L}$ & -0.000039 & -0.3077 \\
$A_{F}$ & $0.000301 * * *$ & 7.0388 \\
\hline
\end{tabular}

*Statistically significant at the $10 \%$ level. $* *$ Statistically significant at the $5 \%$ level. $* * *$ Statistically significant at the $1 \%$ level. 
Table 2

Estimated conjectural elasticity $(\theta), 1973-1998$

\begin{tabular}{|c|c|}
\hline Year & Conjectural elasticity \\
\hline 1973 & 0.13147 \\
\hline 1974 & 0.13201 \\
\hline 1975 & 0.13204 \\
\hline 1976 & 0.13201 \\
\hline 1977 & 0.13209 \\
\hline 1978 & 0.13212 \\
\hline 1979 & 0.13215 \\
\hline 1980 & 0.13237 \\
\hline 1981 & 0.13252 \\
\hline 1982 & 0.13255 \\
\hline 1983 & 0.13246 \\
\hline 1984 & 0.13234 \\
\hline 1985 & 0.13226 \\
\hline 1986 & 0.13214 \\
\hline 1987 & 0.13204 \\
\hline 1988 & 0.13194 \\
\hline 1989 & 0.13180 \\
\hline 1990 & 0.13171 \\
\hline 1991 & 0.13167 \\
\hline 1992 & 0.13167 \\
\hline 1993 & 0.13159 \\
\hline 1994 & 0.13146 \\
\hline 1995 & 0.13132 \\
\hline 1996 & 0.13121 \\
\hline 1997 & 0.13111 \\
\hline 1998 & 0.13085 \\
\hline
\end{tabular}

This result is similar to Wolfram (1999) who conducted an empirical study of market power in the British electricity industry. Since British suppliers also faced inelastic industry demand, most oligopoly models predict prices in excess of marginal costs. While Wolfram found that prices were greater than marginal costs, full advantage was not taken of inelastic demand to raise prices as high as the models predict. She concludes (1999, p. 805), that "Regulatory constraints, the threat of entry, and financial contracts between the suppliers and their customers are considered as possible explanations for the observed price levels".

If the deregulation movement that began in 1995 actually made electricity markets less concentrated, then the value of $\theta$ should decrease after 1995. Inspection of the $\theta$ estimates

Table 3

Test for of null $(\theta=0)$

\begin{tabular}{ll}
\hline Restriction: $A_{0}=A_{L}=A_{F}=A_{K}=0$ & 107.465 \\
\hline$\hat{\theta}$ evaluated at the sample mean & $\hat{\theta}=0.131855(0.000771)$ \\
$99 \%$ left-side confidence interval for $\hat{\theta}$ & $\hat{\theta}>0.128966$ \\
Monopoly Test & $\hat{\theta}<0.134744$ \\
$99 \%$ right-side confidence interval for $\hat{\theta}$ & \\
\hline
\end{tabular}

$\chi^{2}$ statistic $\left(\chi_{(4), 0.01}^{2}=13.3\right)$. 
shows that $\hat{\theta}$ fell from 0.131324 in 1995 to 0.130852 in 1998 , consistent with increased competition. We separated the data into to sets, pre-1996 data and 1996-1998 data. We evaluated $\hat{\theta}$ at the sample means. The pre-1996 $\hat{\theta}$ value was 0.131993 , while the $1996-$ $1998 \hat{\theta}$ value was 0.131058 .

Estimates of the conjectural elasticity term indicate that the electric utility industry is neither perfectly competitive nor monopolistic. The industry does not charge monopoly prices based on own-price elasticity estimates. This is probably due to the regulatory scrutiny and the potential entrants that the industry faces. More important is the long-term trend: the conjectural elasticity estimates peaked in 1982 and fell steadily thereafter, suggesting a decrease in market concentration. The conjectural elasticity estimate has continued to decline since 1995, when formal deregulation of wholesale markets began to be implemented. This suggests that the effects of these recent policies may be more modest than previously acknowledged.

\section{A structural approach}

The CV approach is based on a reduced-form model. To check the robustness of our results, we tried to replicate them using a structural model. The structural model uses a translog cost function to estimate the Lerner Index (LI), a standard measure of industry concentration. The LI is defined simply as the difference between industry price and industry marginal cost, all divided by industry price. A perfectly competitive industry has a LI of zero, while a purely monopolistic industry has a LI of 1.

We estimate the LI for the US electricity industry. We estimate the marginal cost of producing aggregate electricity for the three primary consumer classes (residential, commercial, and industrial) and compare the marginal-cost estimate to the observed composite electricity markets. The marginal-cost estimates and observed prices are used to construct the Lerner Index for the electric utility industry to shed light on the trend of monopoly power in the electricity market.

\subsection{Translog models of electricity production}

We begin with the translog production function proposed by Christensen et al. (1973). This is a flexible form that allows for increasing or decreasing returns to scale and makes no assumption regarding homogeneity or input substitutability. The translog belongs to a class of functions that Blackorby et al. (1977) refer to as general quadratic flexible forms. A three-input version of the translog production function (Beattie and Taylor, 1985, p. 66) takes the form

$$
Q=b_{0} x_{1}^{a_{1}} e^{b_{1} x_{1}} x_{2}^{a_{2}} e^{b_{2} x_{2}} x_{3}^{a_{3}} e^{b_{3} x_{3}}
$$

where $Q$ represents output, $x_{1}, x_{2}$, and $x_{3}$ represent the three inputs, and the $a$ 's and $b$ 's are parameters. According to Beattie and Taylor (1985, p. 249) the derivation of the indirect cost function from the translog production function is mathematically intractable. The 
translog production function must be approximated by a second-order Taylor-series expansion,

$$
\ln Q=b_{0}+b_{i} \sum_{i} \ln x_{i}+\frac{1}{2} b_{i j} \sum_{i} \sum_{j} \ln x_{i} \ln x_{j} .
$$

A time component is usually introduced into (33) to account for technological change. Since the production function is a second-order approximation, both $t$ and $t^{2}$ are added to the equation (Coelli et al., 1998, p. 36). The addition of the technological change component allows (33) to be re-written as

$$
\ln Q=b_{0}+b_{i} \sum_{i} \ln x_{i}+\frac{1}{2} b_{i j} \sum_{i} \sum_{j} \ln x_{i} \ln x_{j}+b_{t} t+b_{t t} t^{2} .
$$

The annual percentage change in output resulting from technological change is estimated by taking the partial derivative of (34) with respect to time:

$$
\frac{\partial \ln Q}{\partial t}=b_{t}+2 t b_{t t}
$$

The technological change format of (34) and (35) assumes Hicks-neutral technological change, which assumes that the shape of the isoquant does not does not change over time, and the marginal products of each input do not change. The Hicks-neutral cost function corresponding to (34) is

$$
\begin{aligned}
\ln c^{*}= & b_{0}+b_{Q} \ln Q+\sum_{i} b_{i} \ln w_{i}+\sum_{i} b_{Q i} \ln Q \ln w_{i}+\frac{1}{2} \sum_{i} \sum_{j} b_{i j} \ln w_{i} \ln w_{j} \\
& +\frac{1}{2} b_{Q Q}(\ln Q)^{2}+b_{t} t+b_{t t} t^{2}+v .
\end{aligned}
$$

Eq. (36) can be modified to account for non-neutral technological change by adding regressors that capture the cross effects of the inputs with time, and output with time, $b_{k t} \ln w_{k} t+b_{l t} \ln w_{l} t+b_{f t} \ln w_{f} t+b_{Q t} \ln Q t$. The modified version of (36) appears as

$$
\begin{aligned}
\ln c^{*}= & b_{0}+b_{Q} \ln Q+\sum_{i} b_{i} \ln w_{i}+\sum_{i} b_{Q i} \ln Q \ln w_{i}+\frac{1}{2} \sum_{i} \sum_{j} b_{i j} \ln w_{i} \ln w_{j} \\
& +\frac{1}{2} b_{Q Q}(\ln Q)^{2}+\sum_{i} b_{i t} \ln w_{i} t+b_{Q t} \ln Q t+v .
\end{aligned}
$$

The large number of parameter estimates can lead to degrees-of-freedom or multicollinearity problems that will cause the estimates to be inefficient. Christensen and Greene (1976), following Zellner (1962), use Seemingly Unrelated Regression (SUR) to obtain more efficient estimates. The cost function is estimated simultaneously with the input demand equations which are derived by using Shepherd's lemma. Cost- 
share equations are the dependent variables in the input demand equations. The cost shares are

$$
\begin{aligned}
& s_{k}=\left(w_{k} x_{k} / c\right)=b_{k} b_{k k} \ln w_{k}+b_{k l} \ln w_{l}+b_{k f} \ln w_{f}+b_{k q} \ln Q+v_{k}, \\
& s_{l}=\left(w_{l} x_{l} / c\right)=b_{l}+b_{l l} \ln w_{l}+b_{l k} \ln w_{k}+b_{l f} \ln w_{f}+b_{l q} \ln Q+v_{l}, \\
& s_{f}=\left(w_{f} x_{f} / c\right)=b_{f}+b_{f f} \ln w_{f}+b_{f k} \ln w_{k}+b_{f l} \ln w_{l}+b_{f q} \ln Q+v_{f} .
\end{aligned}
$$

One of the share equations must be dropped for the SUR estimation procedure to yield efficient maximum likelihood estimates. The results are the same regardless of which share equation is dropped.

The efficiency of parameter estimates is increased by placing restrictions on the cost function. Possible restrictions include homogeneity of degree one in prices, homotheticity, and homogeneity. If the cost function is derived from the neoclassical model, then the cost function should be homogeneous of degree one in prices. Homotheticity is imposed by the restriction $b_{Q i}=0$ (Eq. (37)). Likewise if $b_{Q Q}=0$, then homogeneity is also imposed. The SUR approach combined with the restricting of the cost function can mitigate the degreesof-freedom problem.

Once the degrees-of-freedom problem is dealt with, the problem of how to allocate costs properly among the different customer classes arises. Electricity price and quantity data are disaggregated among the three primary customer classes, commercial, industrial and residential. If a given customer class purchases more electricity during peak hours, then it is inappropriate to assume that marginal generation costs are the same for all customers.

There is considerable evidence that instead of allocating marginal costs among customer classes by the percentage of electricity output that each class purchases, a multiple-output production model would be more appropriate. This approach was suggested by Joskow and Schmalensee (1983).

Hayashi et al. (1985) estimate marginal costs in a multi-output approach to study quasioptimal pricing rules under rate-of-return regulation. They find that prices were not quasioptimal, and that alternative pricing arrangements could be welfare-enhancing.

Karlson (1986) tests the separability of inputs and outputs and determines that the multi-output approach was appropriate. Karlson estimates a translog production possibility frontier (PPF) among the three types of electricity output. He derives the marginal rates of transformation among outputs, and the marginal products of each input from the PPF. Each marginal rate of transformation equation and marginal product equation contain a separability term, $\varphi_{m j}$ between each output and each input. If the joint null hypothesis of separability,

$$
H_{0}: \phi_{m j}=0, \text { for all } m, \text { and all } j
$$

is rejected, then the multiple-output approach would be appropriate. Although Karlson find that none of the individual separability terms were significantly different from zero, he find that the joint null could be rejected well above the $99 \%$ significance level. This suggests that electricity should be modeled as a multiple-output activity, and that the electricity output should be distinguished by its customer class. 
Estimation of marginal costs requires that a modification be made to the translog cost function in (37), since total costs should be estimated by the multi-output translog cost rather than the single-output version of (43). The multi-output translog cost function used by Burgess (1974) and Caves et al. (1980) is

$$
\begin{aligned}
\ln c^{*}= & \alpha_{0}+\sum_{i} \alpha_{i} \ln Q_{i}+\sum_{i} \beta_{i} \ln w_{i}+\frac{1}{2} \sum_{i} \sum_{j} \alpha_{i j} \ln Q_{i} \ln Q_{j} \\
& +\frac{1}{2} \sum_{i} \sum_{j} \beta_{i j} \ln w_{i} \ln w_{j}+\sum_{i} \sum_{j} \rho_{i j} \ln w_{j} .
\end{aligned}
$$

The cost-share equation for each input is

$$
s_{i}=\beta_{i}+\sum_{j} \beta_{i j} \ln w_{j}+\sum_{j} \rho_{i j} \ln Q_{j}+v_{i}
$$

The derivation of the marginal costs by product class is not as apparent since the derivative $(\partial \ln C) /\left(\partial \ln Q_{i}\right)$ is in the form of an elasticity (where $\mathrm{mc}_{i}=$ the marginal cost of the $i$ th output).

$$
\frac{\partial \ln C}{\partial \ln Q_{i}}=\mathrm{mc}_{i} \frac{Q_{i}}{c}=\alpha_{i}+\sum_{j} \alpha_{i j} \ln Q_{j}+\sum_{j} \rho_{i j} \ln w_{j} .
$$

To obtain the marginal cost of the $i$ th output, $(\partial \ln C) /\left(\partial \ln Q_{i}\right)$ needs to be multiplied by $(c) /\left(Q_{i}\right)$. The marginal cost of the $i$ th output is

$$
m c_{i}=\left(\alpha_{i}+\sum_{j} \alpha_{i j} \ln Q_{j}+\sum_{j} \rho_{i j} \ln w_{j}\right) \frac{c}{Q_{i}} .
$$

The marginal cost estimates in (45) are used to construct Lerner Index for each of the customer markets.

\subsection{Estimation procedure}

We use a version of (45) to estimate the Lerner Index for the residential, commercial and industrial electricity markets. The technology is assumed to be Hicksneutral. A three-input, three-output estimation of (45) requires the estimation of 30 parameters (including time and time-squared), which leaves few degrees of freedom. To mitigate this potential problem, we impose homotheticity and homogeneity restrictions on the model. The homotheticity assumption restricts the output-input interaction terms $\rho_{i j}=0$, and eliminates 9 of the 30 parameters. The homogeneity assumption restricts the interaction term between the various outputs $\alpha_{i i}=0$, and eliminates an additional three parameters (since there are three electricity outputs). The combined homotheticity and homogeneity restrictions reduce the number of parameter estimates from 30 to 18 . 
The restricted version of (44) with inputs capital $(K)$, labor $(L)$, and fuel $(F)$, and outputs commercial $\left(Q_{\mathrm{C}}\right)$, residential $\left(Q_{\mathrm{R}}\right)$, and industrial electricity $\left(Q_{\mathrm{I}}\right)$ is

$$
\begin{aligned}
\ln c^{*}= & \alpha_{0}+\alpha_{\mathrm{C}} \ln Q_{\mathrm{C}}+\alpha_{\mathrm{R}} \ln Q_{\mathrm{R}}+\alpha_{\mathrm{I}} \ln Q_{\mathrm{I}}+\beta_{K} \ln w_{K}+\beta_{L} \ln w_{L}+\beta_{F} \ln w_{F} \\
& +\alpha_{\mathrm{CR}} \ln Q_{\mathrm{C}} \ln Q_{\mathrm{R}}+\alpha_{\mathrm{CI}} \ln Q_{\mathrm{C}} \ln Q_{\mathrm{I}}+\alpha_{\mathrm{RI}} \ln Q_{\mathrm{R}} \ln Q_{\mathrm{I}} \\
& +\frac{1}{2}\left[\beta_{K K}\left(\ln w_{K}\right)^{2}+\beta_{L L}\left(\ln w_{L}\right)^{2}+\beta_{F F}\left(\ln w_{F}\right)^{2}\right]+\beta_{K L} \ln w_{K} \ln w_{L} \\
& +\beta_{K F} \ln w_{K} \ln w_{F}+\beta_{L F} \ln w_{L} \ln w_{F}+\beta_{t} t+\beta_{t t} t^{2}
\end{aligned}
$$

Eq. (46) is estimated by SUR. The inclusion of input cost-share equations in the system reduces the degrees of freedom problem. The input cost-share equations are identical to (43) except that the $\rho_{i j}=0$, due to the homotheticity restriction. The restricted cost-share equations are

$$
s_{i}=\beta_{i}+\sum_{j} \beta_{i j} \ln w_{j}+v_{i}
$$

Once the parameter estimates are determined, they can be used to estimate the marginal costs of producing electricity. The marginal cost estimates are identical to (45) except that once again the $\rho_{i j}$ term is dropped. The modified version of (45) that does not include the $\rho_{i j}$ term is

$$
\mathrm{mc}_{i}=\left(\alpha_{\mathrm{I}}+\sum_{j} \alpha_{i j} \ln Q_{j}\right) \frac{c}{Q_{i}} .
$$

Once the marginal cost has been estimated, we can calculate the Lerner Index. Since customer class data is collinear, we estimate only aggregate electricity marginal price rather than separate estimates by customer class.

\subsection{Results}

Translog estimates of aggregate electricity were completed. A single-output version of (46) has the form

$$
\begin{aligned}
\ln c^{*}= & \alpha_{0}+\alpha_{Q} \ln Q+\beta_{K} \ln w_{K}+\beta_{L} \ln w_{L}+\beta_{F} \ln w_{F} \\
& +\frac{1}{2}\left[\beta_{K K}\left(\ln w_{K}\right)^{2}+\beta_{L L}\left(\ln w_{L}\right)^{2}+\beta_{F F}\left(\ln w_{F}\right)^{2}\right]+\beta_{K L} \ln w_{K} \ln w_{L} \\
& +\beta_{K F} \ln w_{K} \ln w_{F}+\beta_{L F} \ln w_{L} \ln w_{F}+\beta_{Q t} \ln Q t+\beta_{t} t+\beta_{t t} t^{2} .
\end{aligned}
$$

The total electricity marginal cost estimate can be compared to actual prices. Estimated marginal costs can be compared to the observed total electricity price to investigate whether the industry has become less concentrated. The SUR estimates for Eq. (46) appear in Table 4. We use the same data set described earlier.

The aggregate electricity price, estimated marginal production cost, and price-cost margin or Lerner Index are evaluated for the 1980s and 1990s period in Table 5. The 
Table 4

Translog total electricity parameter estimates

\begin{tabular}{lcr}
\hline Variable & Parameter estimate & $t$-Statistic \\
\hline$A_{0}$ & -2.775998 & -0.948021 \\
$\alpha_{Q}$ & $0.433765^{* *}$ & 2.030211 \\
$\beta_{K}$ & $-0.333823^{* *}$ & -2.179726 \\
$\beta_{L}$ & $6.607682^{* * *}$ & 11.76475 \\
$\beta_{F}$ & -0.064516 & -1.031417 \\
$\beta_{K K}$ & $0.098037^{* *}$ & 2.471167 \\
$\beta_{L L}$ & $-2.396696^{* * *}$ & -8.455533 \\
$\beta_{F F}$ & $0.026673^{* * *}$ & 3.866116 \\
$\beta_{K L}$ & 0.045613 & 1.359360 \\
$\beta_{K F}$ & -0.015025 & -1.274965 \\
$\beta_{F L}$ & 0.009633 & 0.900644 \\
$\beta_{Q t}$ & 0.000178 & 0.220245 \\
$\beta_{t}$ & $0.036332^{*}$ & 1.987557 \\
$\beta_{t t}$ & $-0.002056^{* * *}$ & -2.737459 \\
\hline
\end{tabular}

*Statistically significant at the $10 \%$ level. $* *$ Statistically significant at the $5 \%$ level. $* * *$ Statistically significant at the $1 \%$ level.

estimated price-cost margins (or Lerner Index) fell from about 0.22 in 1981 to 0.05 in 1998. The downward trend suggests that the industry was becoming less concentrated during that period. The Lerner Index in electric industry fluctuated moderately from 1988 to 1994, increased from 1995 to 1997, then decreased in 1998. Any effectiveness of the electricity restructuring legislation was not seen until 1998, when the Lerner Index fell, although it was still higher than several years from 1987 to 1997.

Table 5

Aggregate electricity price, estimated marginal production cost, and Lerner Index, 1981-1998

\begin{tabular}{|c|c|c|c|}
\hline Year & Total electricity price ${ }^{a}$ & Estimated marginal production $\operatorname{cost}^{\mathrm{a}}$ & Lerner Index or price-cost margin \\
\hline 1981 & 5.5 & 4.307 & 0.21676 \\
\hline 1982 & 6.1 & 4.981 & 0.18336 \\
\hline 1983 & 6.3 & 5.332 & 0.15353 \\
\hline 1984 & 6.25 & 5.453 & 0.12747 \\
\hline 1985 & 6.44 & 5.858 & 0.09032 \\
\hline 1986 & 6.44 & 6.140 & 0.04655 \\
\hline 1987 & 6.37 & 6.260 & 0.01714 \\
\hline 1988 & 6.35 & 5.968 & 0.06003 \\
\hline 1989 & 6.45 & 6.218 & 0.03587 \\
\hline 1990 & 6.57 & 6.290 & 0.04258 \\
\hline 1991 & 6.75 & 6.474 & 0.04088 \\
\hline 1992 & 6.82 & 6.584 & 0.03450 \\
\hline 1993 & 6.93 & 6.561 & 0.05323 \\
\hline 1994 & 6.91 & 6.662 & 0.03581 \\
\hline 1995 & 6.89 & 6.513 & 0.05467 \\
\hline 1996 & 6.86 & 6.397 & 0.06749 \\
\hline 1997 & 6.85 & 6.244 & 0.08842 \\
\hline 1998 & 6.74 & 6.398 & 0.05072 \\
\hline
\end{tabular}

\footnotetext{
${ }^{a}$ Cents per kilowatt hour.
} 
Table 6

Lerner estimates for selected industries

\begin{tabular}{lll}
\hline Author (Year) & Industry & Lerner Index \\
\hline Bresnahan (1982) & Automobiles & $0.100-0.340$ \\
Appelbaum (1982) & Rubber & 0.049 \\
& Textile & 0.072 \\
& Electrical Machinery & 0.198 \\
& Tobacco & 0.648 \\
Porter (1983) & Railroads (in collusive phase) & 0.40 \\
Lopez (1984) & Food Processing & 0.504 \\
Roberts (1984) & Coffee Roasting (largest/second largest firms) & $0.055 / 0.025$ \\
Spiller and Favro (1984) & Banks (Regulated, large firms/small firms) & $0.88 / 0.21$ \\
& Banks (Deregulated, large firms/small firms) & $0.40 / 0.16$ \\
Suslow (1986) & Aluminum & 0.590 \\
Slade (1995) & Retail Gasoline & 0.100 \\
Karp and Perloff (1989a) & Rice Exports (largest estimate) & 0.11 \\
Karp and Perloff (1989b) & Small Black and White TVs in Japan & 0.58 \\
Buschena and Perloff (1991) & Philippines Coconut Oil & 0.89 \\
Wann and Sexton (1992) & Fruit Cocktail & 1.41 \\
Gasmi et al. (1992) & Soft Drinks (Coke/Pepsi post 1976) & $0.64 / 0.56$ \\
Ellison (1994) & Railroads (in collusive phase) & 0.472 \\
Deodhar and Sheldon (1995) & German Bananas & 0.26 \\
Taylor and Zona (1997) & AT\&T (long-distance telephony) & 0.88 \\
Genesove and Mullin (1998) & Sugar Refining 1880-1914 & 0.05 \\
Hyde and Perloff (1998) & Australian Retail Meats & 0
\end{tabular}

Sources: The above studies are cited in part or whole in Bresnahan (1989, Table 17.1, p. 1051), Carlton and Perloff (2005, Table 8.7, p. 277), and in Church and Ware (2000, Table 12.4, p. 447).

To see how these estimates of the Lerner Index for the US electric industry compare to other industries, Table 6 summarizes recent evidence on Lerner indices in various industries, some of which exhibit considerable monopoly power. The table shows the authors, date of publication, and estimated Lerner Index. ${ }^{7}$ In general, the Lerner Index for the US electricity industry is considerably lower than that of most of the industries shown in Table 6.

\section{Summary and conclusion}

A nationwide movement to deregulate (more precisely, restructure) electric utilities emerged in the 1990s. The process gained momentum on December 20, 1995, when the California Public Utility Commission (CPUC) issued an opinion that California electricity consumers should be able to choose their provider by 2003. On September 23, 1996, California Governor Pete Wilson signed Assembly Bill 1890 into law, mandating a 10\% rate cut for most electricity customers, and allowing most customers to choose their

\footnotetext{
${ }^{7}$ Wolfram (1999, Table 1, p. 813) shows numerous values for price-cost markups for the British electricity industry. The British electricity prices are generally more than $20 \%$ above marginal costs, but are well below these predicted in traditional oligopoly models for an industry facing an inelastic demand. Of course, the UK is not like the US in that the UK rivals compete in a unified, national market.
} 
provider by 1998 (LaBorde, 1998: R8). In the wake of California's action, legislation to deregulate electric utilities has been proposed or adopted in every state in the country. However, there is concern that California's subsequent energy crisis may be in part the result of rushing the deregulating of the retail electric markets (see, e.g., Smith, 2000). If California is a bellwether for what other states may face in their deregulated markets, the deregulation movement may be arrested or slowed considerably. According to Joskow (2001), the problem in California was not inherent with deregulation, but rather with the way California implemented its reforms combined with "a good deal of bad luck and ineffective government responses." Making competition more intense has proved to more difficult that states anticipated, largely because erratic wholesale prices have increased retail rates and a credit crunch has decreased the pool of competitors (see, e.g., Smith, 2005).

While not directly addressing broader issues related to competition per se, we find compelling evidence that the electric industry was becoming less concentrated during the 1980 s, before the reforms discussed above were implemented. In the 1990 s, the picture is less clear. Our estimated Lerner Index fell steadily from 1981 to 1987, fluctuated moderately from 1988 to 1994, increased from 1995 to 1997, and fell again in 1998 . According to the conjectural variation approach, the electricity industry has become gradually and consistently less concentrated from 1982 to 1998. Indeed, the CV parameter is steadily declining long before deregulation, and the rate of decline following 1995 is about the same as that before 1995. Perhaps it is too early to tell what deregulation has accomplished or will accomplish in the future, but it is clear that electricity markets were opening up even before the formal deregulation of the late 1990s.

Thus, our results are consistent with the view that deregulation has (so far) not had a measurable effect on economic performance. This leaves us with a mystery. Why was the industry gradually becoming less concentrated without major changes in the regulatory framework? Was it technological or organizational change, or changes in de facto regulation that are difficult to discern? This problem has not really been addressed in the prior literature. In a sense, our results weaken the case for formal deregulation, or at least suggest that competition was gradually being introduced anyway, even without deliberate action by regulators. Of course, we ignore important controversies over the "meaning of competition" (Hayek, 1948), such as actual versus potential competition, static equilibrium versus dynamic process notions of competition, and the like (Machovec, 1995). Still, our findings suggest that the story of electricity restructuring in the 1990s is more subtle and complex than is often recognized.

\section{Acknowledgements}

We thank Fred Bateman, Charles DeLorme, William Lastrapes, and David Robinson for helpful comments and suggestions.

\section{References}

Appelbaum, E., 1979. Testing price taking behavior. Journal of Econometrics 9, 283-294.

Appelbaum, E., 1982. The estimation of the degree of monopoly power. Journal of Econometrics 19, $287-299$. Beattie, BR., Taylor, R.C., 1985. The Economics of Production. John Wiley \& Sons, New York. 
Blackorby, C., Primont, D., Russell, R.R., 1977. On testing separability restrictions with flexible functional forms. Journal of Econometrics 5, 195-209.

Bresnahan, T.F., 1982. The oligopoly solution concept is identified. Economics Letters 10, 87-92.

Bresnahan, T.F., 1989. Empirical studies of industries with market power. In: Schmalensee, R., Willig, R. (Eds.), Handbook of Industrial Organization. North-Holland, Amsterdam, pp. 1011-1057.

Burgess, D.F., 1974. A cost minimization approach to import demand equations. Review of Economics and Statistics 56, 225-234.

Buschena, D.E., Perloff, J.M., 1991. The creation of dominant firm market power in the coconut oil export market. American Journal of Agricultural Economics 73, 1000-1008.

Carlton, D.W., Perloff, J.M., 2005. Modern Industrial Organization, 4th ed. Addison-Wesley, New York.

Caves, D.W., Christensen, L.R., Tretheway, M.W., 1980. Flexible cost functions for multi-product firms. Review of Economics and Statistics 62, 477-481.

Christensen, L.R., Greene, W.H., 1976. Economies of scale in US electric power generation. Journal of Political Economy 84 (4), 655-676.

Christensen, L.R., Jorgenson, D., Lau, L.J., 1973. Transcendental logarithmic production frontiers. Review of Economics and Statistics 55, 28-45.

Church, J.M., Ware, R., 2000. Industrial Organization. Irwin McGraw Hill, Homewood, IL.

Coelli, T., Rao, D.S.P., Battese, G.E., 1998. An Introduction to Efficiency and Productivity Analysis. Kluwer Academic Publishers, Boston.

Cowling, K., Waterson, M., 1976. Price-cost margins and market structure. Economica 43, $267-274$.

Danielson, A.L., Gupta, N.K., Klein, P.G., 1999. Contracts and the institutional environment for electricity reform. Electricity Journal 12, 51-60.

Daughety, A.F., 1985. Reconsidering Cournot: the Cournot equilibrium is consistent. Rand Journal of Economics $16,368-379$.

Deodhar, S.Y., Sheldon, I.M., 1995. Is foreign trade (im)perfectly competitive?: an analysis of the German market for banana Imports. Journal of Agricultural Economics 46 (3), 336-348

Diewert, W.E., 1971. An application of the Shepherd duality theorem: a generalized Leontief production function. Journal of Political Economy 79, 481-507.

Ellison, G., 1994. Theories of cartel stability and the joint executive committee. Rand Journal of Economics 25, 37-57.

Fischer, T., Kamerschen, D.R., 2003. Price-cost margins in the US airline industry using a conjectural variation approach. Journal of Transport Economics and Policy 37, 225-258.

Gasmi, F., Laffont, J.J., Vuong, Q., 1992. Econometric analysis of collusive behavior in a soft drink market. Journal of Economics and Management Strategy 1, 277-311.

Genesove, D., Mullin, W., 1998. Testing static oligopoly models: conduct and cost in the sugar industry, 18901914. Rand Journal of Economics 29, 355-377.

Gorman, W.M., 1953. Community preference fields. Econometrica 21, 63-80.

Hayashi, P.M., Sevier, M., Trapani, J.M., 1985. Pricing efficiency under rate-of-return regulation: some empirical evidence for the electric utility industry. Southern Economic Journal 51, 76-792.

Hayek, F.A., 1948. The meaning of competition. Hayek, Individualism and Economic Order. University of Chicago Press, Chicago, pp. $92-106$.

Hyde, C.E., Perloff, J.M., 1998. Multi-market market power estimation: the Australian retail meat sector. Applied Economics 30, 1169-1176.

Iwata, G., 1974. Measurement of conjectural variations in oligopoly. Econometrica 42, 267-274.

Joskow, P., 2001. California's electricity crisis, NBER Working Paper No. 8442.

Joskow, P., Schmalensee, R., 1983. Markets for Power: An Analysis of Electrical Utility Deregulation. MIT Press, Cambridge, MA.

Kamerschen, D.R., Porter, D.V., 2004. The demand for residential, industrial and total electricity, 1973-1998. Energy Economics 26, 87-100.

Karlson, S.H., 1986. Multiple-output production and pricing in electric utilities. Southern Economic Journal 53, $73-86$.

Karp, L.S., Perloff, J.M., 1989a. Oligopoly in the rice export market. The Review of Economics and Statistics 71, 462-470. 
Karp, L.S., Perloff, J.M., 1989b. Estimating market structure and tax incidence: the Japanese television market. The Journal of Industrial Economics 37, 225-239.

LaBorde, A., 1998. Power unbound: learning the hard way. Wall Street Journal R8 (September 14).

Lopez, R.E., 1984. Measuring oligopoly power and production responses of the Canadian food processing industry. Journal of Agricultural Economics 35, 219-230.

Machovec, F., 1995. Perfect Competition and the Transformation of Economics. Routledge, New York.

Porter, R., 1983. A study of cartel stability: the joint executive committee, 1880-1886. Bell Journal of Economics $14,301-314$.

Roberts, M.J., 1984. Testing oligopolistic behavior. International Journal of Industrial Organization 2, $367-383$.

Slade, M.E., 1995. Empirical games: the oligopoly case. Canadian Journal of Economics 28, 368-402.

Smith, R., 2000. California best by electric shortages. Wall Street Journal A3, 6 (August 3).

Smith, R., 2005. A test of the results of electricity deregulation. Wall Street Journal D5 (March 3).

Spiller, P.T., Favro, E., 1984. The effects of entry regulation on oligopolistic interaction: the Uruguayan banking sector. Rand Journal of Economics 13 (3), 399-401.

Suslow, V.Y., 1986. Estimating monopoly behavior with competitive recycling: an application to Alcoa. Rand Journal of Economics 17, 389-403.

Taylor, W., Zona, J., 1997. An analysis of the state of competition in long-distance telephone markets. Journal of Regulatory Economics 11, 227-255.

Wann, J.J., Sexton, R.J., 1992. Imperfect competition in multiproduct food industries with application to pear processing. American Journal of Agricultural Economics 74 (4), 980-990.

Wolfram, C.D., 1999. Measuring duopoly power in the British electricity spot market. American Economic Review 89 (4), 805.

Zellner, A., 1962. An efficient method for estimating seemingly unrelated regressions and tests for aggregation bias. Journal of the American Statistical Association 57, 585-612. 